\title{
A FRAMEWORK FOR TECHNOLOGY DRIVEN DESIGN: CRITICALITY AND COMFORT ZONE FOR EMERGING TECHNOLOGIES
}

\author{
P. Krus ${ }^{1, \otimes}$ and L. Pereira ${ }^{2}$ \\ ${ }^{1}$ Linköping University, Sweden, ${ }^{2}$ Federal University of ABC, Brazil \\ $\square$ petter.krus@liu.se
}

\section{Abstract}

This paper proposes an analytical framework for estimating the domain where a type of technology can be used in a system. In order to achieve this aim, we have elaborated on the concepts of technology critical, technology sensitive, and the technology comfort zone, to analytically assess the impact of a new technology in the early phases of system design. The result is a general method to indicate the range of requirements that can result in valid designs. This tool can assist in the decision-making processes for technology portfolio selection based on sustainable principles.

Keywords: sustainable design, decision making, technology development

\section{Introduction}

Requirements for sustainable systems often mean that new technological solutions should be introduced (Svetinovic, 2013). In most cases, however, this is not straightforward. According to the multi-level approach, tensions between routine practices, or stabilized forces, and the disruption brought about by alternative technologies are important for assessing and understanding technology transitions (Berggren et al., 2015). In addition, sustainable technologies very often have inherently lower performance than the technologies they replace because a dominant design has not emerged yet (Narayanan and Chen, 2012; Utterback, 1996).

This means that, designers of complex technological systems should consider supply and demand side (Nelson, 2013; Rezaee et al., 2015).

The supply side is concerned with how to organize the feasible concept into the design logic respecting all the parameters and hierarchies of integration (Sheard and Mostashari, 2009). On the other hand, the demand side should deal with societal challenges and expectations. As a result, designers deal with decisions that involve multiple domains related to technology choices, system architecture, and sustainable transition (Cruz-Cázares et al., 2013; Davison et al., 2015).

At the same time, they must be aware of uncertainties related to the innovation process, which affect business models and organizational management (Rantala et al., 2018; Bolton and Hannon, 2016).

As noted above, perhaps the most fundamental question is: what are the paths that guide the designers to decisions about sustainable technology selection, that might eventually become a standard design, and why? Our assumption is that first we need to determine the specific set of requirements for technology. Secondly, it is also important to understand for what type of system the new technology is viable for. In this paper, we address these questions proposing a framework for mapping the valid region of requirements that identifies the applications where the new technology system may be used 
and yield viable designs. We emphasized early design phases associated with key technological capability, application, market segment, and sustainable transition values.

To accomplish this goal, we set out to evaluate the empirical evidence observed in the technological change of complex systems such as aircraft and vehicles. In order to map the domains of valid requirements, we examined the increasing demand for electrical power systems for aircraft and vehicles. The reason this technological domain was chosen is related with the need to reducing greenhouse gas emissions in the transport sector while at the same time maximize energy efficiency (Tariq et al., 2016; Martinez et al., 2017; Naayagi, 2013; Schlabe and Lienig, 2012; Koot et al., 2005).

\section{Transition design for more sustainable technologies}

Technology selection plays a crucial role in driving corporate efforts to support the right investments to achieve critical business goals (Lee et al., 2018). Therefore, choosing and adopting new technology are both capital-intensive and risky strategies that companies have to deal with when they decide to innovate. According to the literature, the decision-making process on technology selection is one of the most challenging tasks in any system development. The reason is related to the cost, as well as the uncertainty, of developing a new system, which is around threequarters of a program's total life cycle (Fernandes et al., 2015; Georgiadis et al., 2013). Actually, most of the cost of a system is determined during the design phase because of multiple iterations, intrinsic (Fernandes et al., 2017; McNerney et al., 2011).

At the base of the design decision-making process, there are the sets of systems requirements that should be managed and developed. Nowadays it is necessary to address the question on how to move from old to new technology together with its impact on human well-being and the environment. Designers are main actors in the process of design a society based on the principles of health promotion, food security, environmental conservation, renewable energy, smart city, inclusive education, and multiculturalism (Zolfagharian et al., 2019; Köhler et al., 2019).

At the subsystem level, the interfaces among design, technology, and management transitions are essential for sustainable system development (Irwin, 2015; Ceschin, 2014; Loorbach, 2010; Geels, 2005). In the last two decades, design scholars have proposed an interdisciplinary approach to sustainable transition, merging it with design theory and practice plus innovation studies (Hyysalo et al., 2019; Gaziulusoy and Erdoğan Öztekin, 2019). Most of the papers presented in the systematic review were concerned with theoretically ground the field of design transition. In this paper, we propose to use model based analytical methods to assess the impact of a new technology in the early phases of system development based on transition design principles.

\section{Technology and requirement space}

How does one model and assess the impact of a new technology in the early phases of design? To answer this question, a mathematical formulation together with some concepts are proposed to evaluate the design criticality in terms of performance and cost. In (Suh, 2001) the design is described as a process of mapping customer requirements into functional requirements that in turn is mapped onto the design parameters. Here we propose that the functional requirements must be part of the Requirement space that is a function of the Technology characteristics.

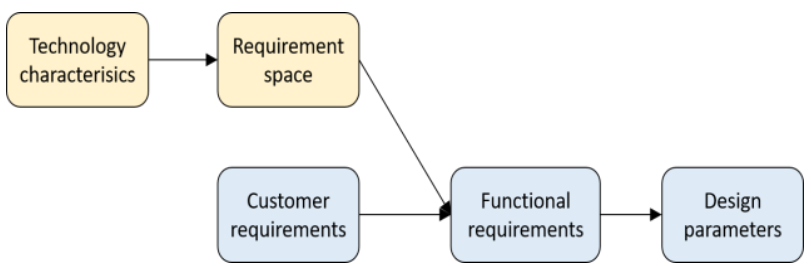

Figure 1. The design process with the Requirement space as a function of the Technology characteristics is indicated

Our assumption is that we can identify requirements where the system design is viable, i.e. that are part of the Technology requirement space. We considered both technology and market aspects. For each 
region, we have a characteristic with an impact on system performance. We called this framework Requirements space, where we can indicate the technology criticality, technology sensitivity and technology comfort zone (Figure 2).

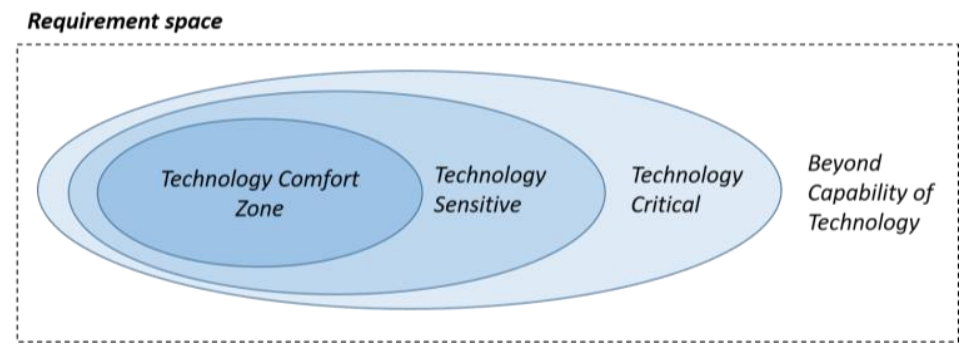

Figure 2. Requirement space framework

\subsection{Technology comfort zone, TCZ, concept}

The technology comfort zone is here defined as the region where it is easy to apply a technology. I.e. it is the region where the requirements can be met with a comfortable margin. In this region, it is not necessary to particularly optimize the product for the technology dependent performance, or the technology is not critical for the performance of the product.

By technology criticality we mean that the cost of modifying a functional characteristic is associated with a high increase in the cost of the product. The definition introduced here for technology criticality is the following:

- Improvement in the technology, $\zeta$, such as e.g. tensile strength, specific energy or power, should have a strong effect on system performance $p$

- The change in a design parameters, $x$, such as size, would have a lower effect on system performance $p$.

- A significant sensitivity from design parameters to cost, $c$, from $x$, making it expensive to increase performance through design parameters.

\subsection{Technology sensitivity}

To study the criticality, it is of interest to analyse the relative sensitivity around a design point, i.e. we want to measure the relative impact of the change in a design parameter on performance. Assuming that the performance can be expressed as:

$$
p=f_{p}(x, \zeta)
$$

The sensitivity of the performance with respect to the design variable xi related to the technology can be expressed using normalized sensitivity:

$$
k_{0, p, i}=\frac{x_{i}}{p} \frac{\partial p}{\partial x_{i}}
$$

\subsection{Cost benefit factor}

Another useful relationship is the relationship between cost and performance.

The system cost is assumed to be expressed in a similar way:

$$
c=f_{c}(\mathbf{x}, \zeta)
$$

Here the sensitivity of the design parameter to cost is also expressed using the normalized sensitivity.

$$
k_{0, c, i}=\frac{x_{i}}{c} \frac{\partial c}{\partial x_{i}}
$$


The cost benefit factor $\kappa_{i}$ of a design parameter $x_{i}$ is now defined as:

$$
\kappa_{i}=\frac{k_{0, p, i}}{k_{0, c, i}}=\left(\frac{x_{i}}{p} \frac{\partial p}{\partial x_{i}}\right)\left(\frac{x_{i}}{c} \frac{\partial c}{\partial x_{i}}\right)^{-1}=\frac{c}{p}\left(\frac{\partial p}{\partial x_{i}}\right)\left(\frac{\partial c}{\partial x_{i}}\right)^{-1}
$$

A working definition used for technology critical is if:

$$
\kappa=\sum_{i=1}^{n} \kappa_{i}<1
$$

A practical definition used for criticality can also be to just look at the design variable with the highest impact, since very often only one design parameter is very dominant.

\subsection{Technology comfort zone concept, TCZ}

The technology comfort zone is the region where it is easy to select parameters, i.e. the region where the requirements can be met with a comfortable margin. In this region, it is not necessary to particularly optimize the product for performance. Instead, to get a competitive product other aspects need to be emphasized.

In the technology comfort zone, the performance is more or less directly proportional to the design parameters. Here, this is defined when the cost benefit factor is more than half an order of magnitude larger than the critical, i.e. $\kappa>3$. In the region in-between we say that the system is technology sensitive.

The assumption made here is that changing the size of a component to change its performance does not involve any development of the technology as such. For instance, increasing the size of a battery to gain capacity does not imply that the technology is advanced. However, if the energy density, which is the amount of energy that can be stored in a battery of a given size, can be boosted, this represents an improvement of the technology as such.

\section{Empirical evidences of critical technology and technology comfort zone}

Electric road vehicles are rapidly becoming popular. This involves a wide range of vehicles from electrified bicycles to electric cars. A critical limitations for electric cars have been there limited range in combination with limited availability of charging stations.

\subsection{The criticality of electric motors for electric vehicles}

The power density of electric motors is well on par with combustion engines. Electric motors typically have specific powers in the order of magnitude of $1 \mathrm{~kW}$ continuously and peak powers at least twice that, and there are motors with much higher power density. Using equation yields a conservative motor weight as:

$$
m_{\text {motor }}=\frac{P_{r e q}}{\varsigma_{m}}=\frac{1000 \times 0.075 m_{v}}{1000}=0.075 m_{v}
$$

The conclusion is that the electric motors is firmly within the comfort zone for vehicles (at least regarding weight). What is of important is the specific torque and the efficiency characteristics, that are of significance to decide if gearboxes are needed or not but this is outside the scope of this paper.

\subsection{The criticality of batteries}

Several electric cars have been introduced in recent years (-2019). They therefore represent an interesting set of data, where the positioning of performance can be studied with respect to criticality. Looking at statistical data and plotting energy consumption per $\mathrm{km}$ as a function of car weight yields the following line (Figure 3). This data is based on manufacturers' data and is probably of variable quality. The prices are quoted in SEK without VAT, since Sweden is in the EU and most cars (as of 
2019) are not subject to any tariffs to penalise cars, and it is a market where most of the electric cars are available. At the time of data collection (2019) 1 EUR is approximately 10 SEK.
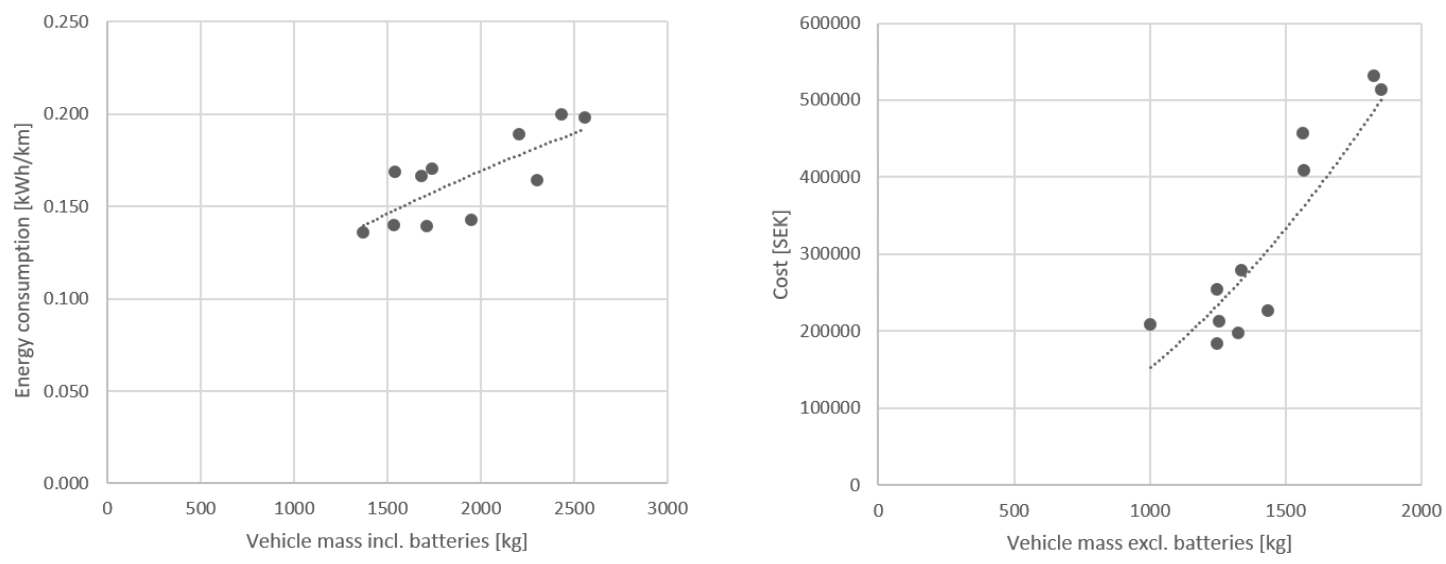

Figure 3. Energy consumption as a function of vehicle mass and net (without battery) vehicle cost as a function of net vehicle mass

The best fit of the data in Figure is identified using regression analysis is:

$$
E_{\text {cons }}=a_{E} m_{\text {tot }}^{b_{E}}=0.004397 m_{\text {tot }}{ }^{0.5163}[\mathrm{kwh} / \mathrm{km}]
$$

The mass includes the battery, $m_{b}$ (in $\mathrm{kg}$ ). It can therefore be expressed as

$$
m_{b}=\frac{E_{b}}{\zeta_{b}}
$$

where $k_{b}$ is the specific power for the battery pack. Although this may vary with different cars we used an estimate of

$$
\varsigma_{b}=0.155[\mathrm{kwh} / \mathrm{kg}]
$$

This is based on an average of some known battery packs. The range of the vehicle can then be estimated as:

$$
R=\frac{E_{b}}{E_{\text {cons }}}=\frac{\varsigma_{b} m_{b}}{a_{E}\left(m_{0}+m_{b}\right)^{b_{E}}}=\frac{35.25 m_{b}}{\left(m_{0}+m_{b}\right)^{0.5163}}
$$

Looking at statistical data in Figure 4 net cost as a function of vehicle net mass (without battery), the following relationship can be found (in $[\mathrm{SEK}]$ ):

$$
c_{0}=a_{c} m_{0}^{b_{c}}=0.00192661 m_{0}^{2.599}[\mathrm{SEK}]
$$

and

$$
c_{b}=k_{b c} E_{b}=k_{b c} \varsigma_{b} m_{b}
$$

where (based on Tesla batteries 2019)

$$
k_{b c}=1282[\mathrm{SEK} / \mathrm{kwh}]
$$

The total cost is then

$$
c_{t}=c_{0}+c_{b}=a_{c} m_{0}^{b_{c}}+k_{b c} m_{b}=0.00192661 m_{0}^{2.599}+444.6 m_{b}[\mathrm{SEK}]
$$


With with $p=R$ and $x=\Psi$, this can be written as:

$$
\kappa=\frac{R}{c_{t}}\left(\frac{\partial c_{t}}{\partial \Psi}\right)\left(\frac{\partial R}{\partial \Psi}\right)^{-1}
$$

With values for the coefficients from the statistical data the diagrams in Figure 4 is obtained. The data show that the existing electrical cars falls in the Technology comfort zone, which confirms that the value of $\kappa>3$ is a good indication of where exiting products can be expected.
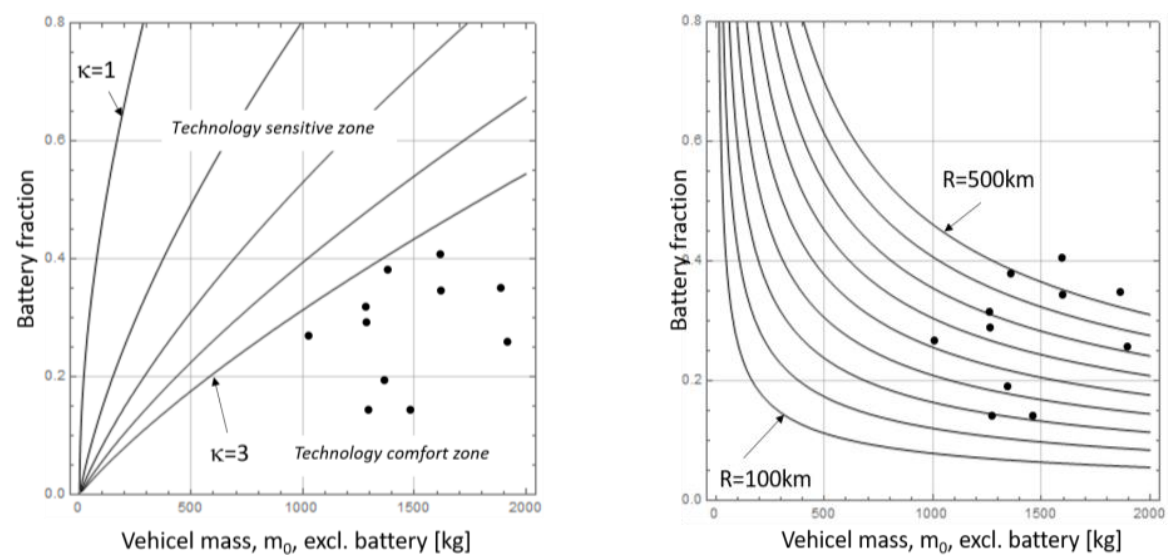

Figure 4. Diagram of the technology zones (left) and range (right). The curves to the left show lines with constant $\kappa$ between 1 and 3.

\section{Technology forecasting}

An important application of studying the technology comfort zone is for technology forecasting. Estimating the performance of technologies for future application can be critical for technology management and product planning. In this example there are two coefficients that are expected to change over time. One is the specific cost of energy storage, $k_{b c}$, and the other is the energy density, $k_{b m}$. Projecting to 2024 the battery cost is set to $94 \mathrm{USD} / \mathrm{kg}$. Extrapolating the increase of energy density from historical data in (Placke et al., 2017) yields an increase of about $3 \mathrm{Wh} / \mathrm{kg} / \mathrm{year}$. The energy density is expected to go from $0.156 \mathrm{kWh} / \mathrm{kg}$ (2019) to $0.1716 \mathrm{kWh} / \mathrm{kg}$ by 2024 . According to BloombergNEF the battery cost at pack level could be as low as $94 \mathrm{USD} / \mathrm{kg}$. Using these numbers the technology comfort zone, TCZ, for 2024 can be estimated. This is shown in Figure 6. Here we can now identify a region where new products can be placed. This is a region that is presently vacant but that is opened up as the technology comfort zone is increased. It means that smaller cars can be produced, with ranges from $300-600 \mathrm{~km}$.
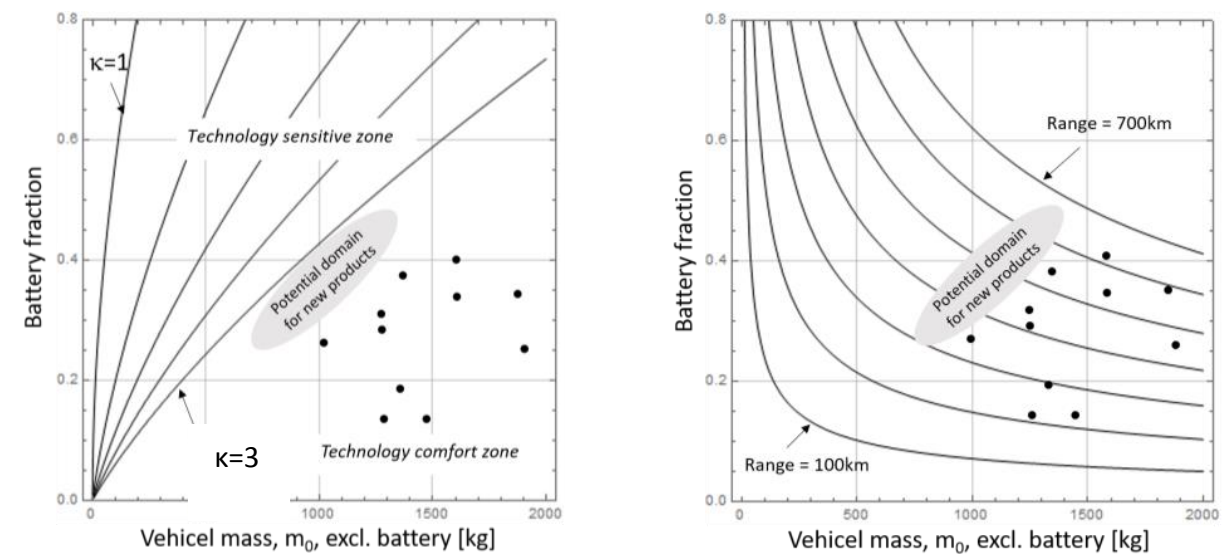

Figure 5. Diagram of the technology zones (left) and range (right) estimated for 2024. The curves show lines with constant $\boldsymbol{\kappa}$ between 1 and 3 . There is a new area where new products are likely to be located. 


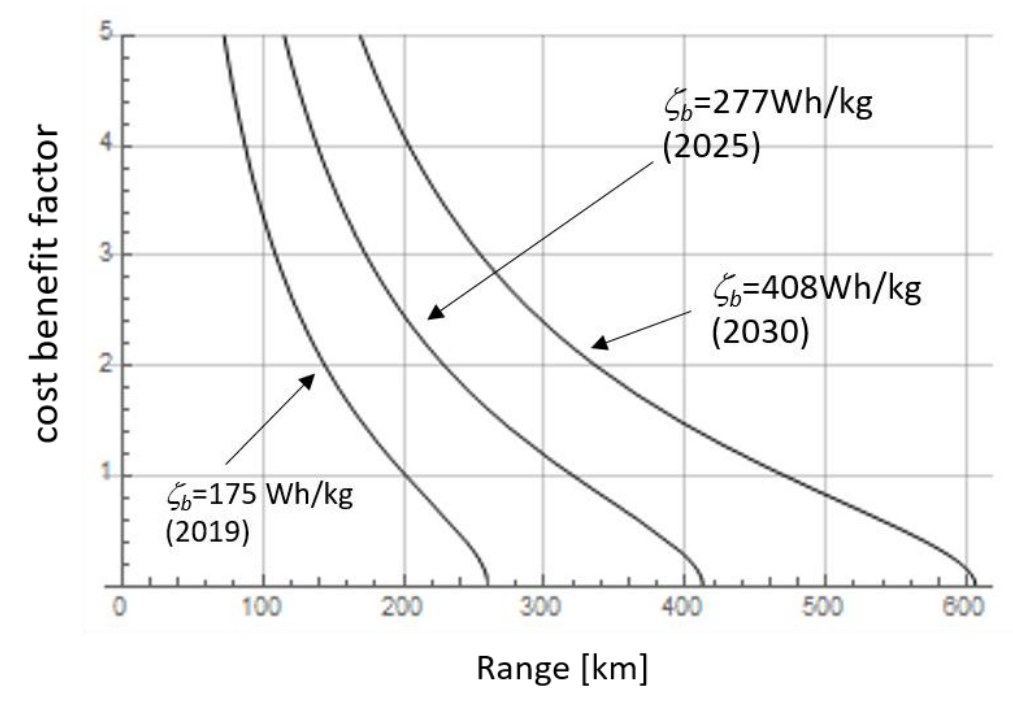

Figure 6. The inverse of cost benefit factor as a function of range. The curves represent 2019 technology and with estimated technology level 2025 and 2030.

\section{The criticality of technology for electric aircraft}

The application of electric drive systems is interesting for various reasons. In addition to the sustainability arguments, there are other important aspects from a user perspective such as the potential for simpler maintenance, lower noise, less vibration etc. Electric propulsion is already the dominant design for small UAVs, both civil and military (Traub, 2011).

In these applications, there are primarily other reasons, such as ease of operation, maintenance and low acoustic signature. In (Hepperle, 2012), it is also argued that electric propulsion is becoming increasingly interesting for larger aircraft. In (Kuhn et al., 2012), hybrid propulsion system and pure electric propulsion systems are studied as options for future aircraft. A critical performance parameter for aircraft applications is range. Both references deal with performance calculations including range, but here the simple approach in (Traub, 2011) is used. There are many technical issues to be resolved in order to have electric propulsion in commercial aircraft but perhaps the most critical performance parameter for the aircraft applications is the range. For a battery-powered aircraft, this can be calculated from first principles as:

$$
R=\frac{\varsigma_{b}}{g} \eta\left(\frac{L}{D}\right) \frac{W_{b}}{W_{0}}
$$

This is very similar to the Breguet range equation except that in the case of fuel, the weight of fuel gradually diminishes during flight. Here $\zeta_{b} \mathrm{~s}$ the energy density of the battery in Joule/Kg. The takeoff weight $W_{0}$ is: $W_{0}=W_{e}+W_{b}+W_{\text {pay }}$. Where $W_{\text {pay }}$ is the payload $W_{b}$ the battery weight and $W_{e}$ is the rest of the weight.

$$
R=\eta_{p} \frac{\varsigma_{b}}{g}\left(\frac{L}{D}\right) \frac{W_{b}}{W_{b}+W_{p a y}+W_{e}}
$$

The impact of the technology can clearly be seen. There are basically four terms. These are the battery energy density $\zeta_{b}$, the propulsive efficiency $\eta_{p}$ (including both efficiency of prop and electrical motor with power control and distribution system), the aerodynamic property L/D and the empty weight $W_{e}$. The impact of the battery energy density on range is:

$$
k_{0, \zeta}=\frac{\varsigma_{b}}{R} \frac{\partial R}{\partial \varsigma_{b}}=\frac{\varsigma_{b}}{R} \frac{\partial}{\partial \varsigma_{b}}\left(\eta_{p} \frac{\varsigma_{b}}{g}\left(\frac{L}{D}\right) \frac{W_{b}}{W_{b}+W_{p a y}+W_{e}}\right)=1
$$


As a measure of cost the total weight is used, since in absence of other information the take-off weight is used as a measure of its cost. It is also assumed that to some extend the batteries can also contribute to the structure, at least not to increase the structural weight (which is a bit optimistic). Furthermore, a non-dimensional battery weight as the design variable

$$
\Psi=W_{b} / W_{1}
$$

where $W_{1}=W_{\text {pay }}+W_{e}$. The range can be written as:

$$
R=\eta \frac{\varsigma_{b}}{g}\left(\frac{L}{D}\right) \frac{\Psi}{1+\Psi}
$$

Normalized cost sensitivity from the design parameter is:

$$
k_{0, c}=\frac{\Psi}{c_{W}} \frac{\partial c_{W}}{\partial \Psi}=\frac{\Psi}{1+\Psi}
$$

The normalized performance sensitivity from the design parameter is:

$$
k_{0, p}=\frac{\Psi}{R} \frac{\partial R}{\partial \Psi}=\frac{\Psi}{R} \frac{\partial}{\partial \Psi}\left(\eta \frac{c_{b}}{g}\left(\frac{L}{D}\right) \frac{\Psi}{1+\Psi}\right)=\frac{1}{1+\Psi}
$$

This means that the technology criticality index is:

$$
\kappa=\frac{k_{0, p}}{k_{0, c}}=\Psi^{-1}
$$

As can be seen, if the battery weight is increased beyond a certain point the design will leave the comfort zone and at some point it turns into a critical technology. In order to investigate the criticality of the technology, typical values are used in the equation. Using typical values means that other technologies are also kept within their comfort zone. Here $\zeta_{b}=175 \mathrm{Wh} / \mathrm{kg}$ at pack level for 2019 is assumed, (corresponding li-ion technology batteries of Tesla), $\eta_{p}=0.9, \mathrm{~L} / \mathrm{D}=20$. An increase in $\mathrm{L} / \mathrm{D}$ would directly affect the range, but it would also mean leaving the technology comfort zone, since L/D of 20 represents very good commercial aircraft.

The plot below shows the normalized sensitivity. According to (Misra, 2018) a more optimistic view on the development of power density driven by the need in aerospace, can be expected. The assumption here is that an annual increase of $8 \%$ can be expected. However, it should also be noted that the range is the maximum range without any reserve, that would be necessary for operation.

\section{Discussion}

In order to demonstrate the methodology, we have empirically demonstrated the criticality of technology as well as estimated the technology comfort zone for electric propulsion on electrical vehicles and then also shown how it can be applied to electric aircraft. The framework proposed has allowed the calculation and the visualization of the requirements needed in order to find the right balance in terms of energy, weight, performance, and cost. Note that the analysis has been carried out with respect to battery energy density and cost. Other factors such as e.g. limitation in battery charging stations or other supporting infrastructure, have not been considered here.

Identifying the sensitivity of a technology at an early stage means that the investments that is needed to develop, or otherwise obtain the required technology level, can be allocated from the onset. When coupled to models for prediction of technology evolution, this can also be used to predict when applications will fall into the technology comfort zone. In this way technology areas for new products can be identified, where it is likely that the performance of the technology does not pose a problem at the time when the product is ready for launch. 
From the perspective of innovation management, the framework can be used as a communication tool with engineering teams since it helps understanding technology processes in a simpler manner. In addition, it is also important for decision making, given it involves the balancing of multiple, potentially conflicting requirements. For future research, it would be interesting to keep testing these concepts with other cases.

\section{Conclusions}

In this paper, we have introduced the concepts of technology critical, technology sensitive and technology comfort zone for mapping requirements where feasible products can be realized. In this way, requirement domains can be identified, where it is likely that the performance of new technology does not become a major concern for the product development, when a technology transition is forced e.g. due to sustainability.

Empirical evidence was obtained by studying how existing electric vehicles have been positioned with respect to range and cost, and it is shown that these are all in the technology comfort zone with respect to battery technology and range. It was also demonstrated how the expected development of technology with respect to cost and performance translates into new domains in the requirement space where new products can be situated. The concept was also used to outline the valid requirement with respect to range for electric aircraft.

\section{References}

Berggren, C., Magnusson, T. and Sushandoyo, D. (2015), "Transition pathways revisited: Established firms as multi-level actors in the heavy vehicle industry", Research Policy, Vol. 44 No. 5, pp. 1017-1028.

Bolton, R. and Hannon, M. (2016), "Governing sustainability transitions through business model innovation: Towards a systems understanding", Research Policy, North-Holland, Vol. 45 No. 9, pp. 1731-1742.

Ceschin, F. (2014), "How the design of socio-technical experiments can enable radical changes for sustainability", International Journal of Design, Vol. 8 No. 3, pp. 1-21.

Cruz-Cázares, C., Bayona-Sáez, C. and García-Marco, T. (2013), "Make, buy or both? R\&D strategy selection", Journal of Engineering and Technology Management, Vol. 30 No. 3, pp. 227-245.

Davison, P., Cameron, B. and Crawley, E.F. (2015), “Technology portfolio planning by weighted graph analysis of system Architectures", Systems Engineering, Vol. 18 No. 1, pp. 45-58.

Fernandes, J. et al. (2015), "Requirements change in complex technical systems: an empirical study of root causes", Research in Engineering Design, Vol. 1 No. 26, pp. 37-55.

Fernandes, J.V. et al. (2017), "Modelling the dynamics of complex early design processes: An agent-based approach", Design Science, Vol. 3, pp. 1-34.

Gaziulusoy, A.İ. and Erdoğan Öztekin, E. (2019), "Design for Sustainability Transitions: Origins, Attitudes and Future Directions", Sustainability, Vol. 11 No. 13, p. 3601.

Geels, F.W. (2005), Technological Transitions and System Innovations, Edward Elgar Publishing.

Georgiadis, D.R., Mazzuchi, T. and Sarkani, S. (2013), "Using Multi Criteria Decision Making in Analysis of Alternatives for Selection of Enabling Technology", Systems Engineering, Vol. 16 No. 3, pp. 287-303.

Hepperle, M. (2012), "Electric Flight - Potential and Limitations", Energy Efficient Technologies and Concepts of Operation, STO, Available at: https://doi.org/10.14339/STO-MP-AVT-209.

Hyysalo, S. et al. (2019), "Codesign for transitions governance: A Mid-range pathway creation toolset for accelerating sociotechnical change”, Design Studies, Elsevier Ltd, Vol. 63 No. June, pp. 181-203.

Irwin, T. (2015), "Transition design: A proposal for a new area of design practice, study, and research", Design and Culture, Vol. 7 No. 2, pp. 229-246.

Köhler, J. et al. (2019), “An agenda for sustainability transitions research: State of the art and future directions", Environmental Innovation and Societal Transitions, Elsevier, Vol. 31 No. February, pp. 1-32.

Koot, M. et al. (2005), "Energy management strategies for vehicular electric power systems", IEEE Transactions on Vehicular Technology, Vol. 54 No. 3, pp. 771-782.

Kuhn, H. et al. (2012), "Progress and perspectives of electric air transport", 28th Congress of the International Council of the Aeronautical Sciences 2012, ICAS 2012, pp. 4886-4899.

Lee, C.Y., Wu, H.L. and Dong, M. (2018), "What Drives Firms to Explore New Technological Fields? An Investigation on the Technological Entry Effect of CEO Decision Horizon and Board Governance", IEEE Transactions on Engineering Management, Vol. 2 No. 66, pp. 142-155.

Loorbach, D. (2010), "Transition management for sustainable development: A prescriptive, complexity-based governance framework”, Governance, Vol. 23 No. 1, pp. 161-183. 
Martinez, C.M. et al. (2017), "Energy Management in Plug-in Hybrid Electric Vehicles: Recent Progress and a Connected Vehicles Perspective", IEEE Transactions on Vehicular Technology, Vol. 66 No. 6, pp. 4534-4549.

McNerney, J. et al. (2011), "Role of design complexity in technology improvement", Proceedings of the National Academy of Sciences, Vol. 108 No. 22, pp. 9008-9013.

Misra, A. (2018), Summary of 2017 NASA Workshop on Assessment of Advanced Battery Technologies for Aerospace Applications. Available at: https://ntrs.nasa.gov/archive/nasa/casi.ntrs.nasa.gov/20180001539.pdf.

Naayagi, R.T. (2013), "A review of more electric aircraft technology", International Conference on Energy Efficient Technologies for Sustainability (ICEETS), IEEE.

Narayanan, V.K. and Chen, T. (2012), "Research on technology standards: Accomplishment and challenges", Research Policy, Vol. 41 No. 8, pp. 1375-1406.

Nelson, R.R. (2013), "Demand, supply, and their interaction on markets, as seen from the perspective of evolutionary economic theory", Journal of Evolutionary Economics, Vol. 23 No. 17, pp. 17-38.

Placke, T. et al. (2017), "Lithium ion, lithium metal, and alternative rechargeable battery technologies: The odyssey for high energy density", Journal of Solid State Electrochemistry, Vol. 21 No. 7, pp. 1939-1964.

Rantala, T. et al. (2018), "The effect of sustainability in the adoption of technological, service, and business model innovations", Journal of Cleaner Production, No. 172, pp. 46-55.

Rezaee, S.A. et al. (2015), "Participatory Demand-supply Systems. Procedia Computer Science", 2015 Conference on Systems Engineering Research, Vol. 44, pp. 105-114.

Schlabe, D. and Lienig, J. (2012), "Energy Management of Aircraft Electrical Systems - State of the Art and Further Directions", International Conference on Electrical Systems for Aircraft, Railway, Ships Propulsion and Road Vehicles (ESARS), pp. 1-6.

Sheard, S.A. and Mostashari, A. (2009), "Principles of complex systems for systems engineering", Systems Engineering, No. 12, pp. 295-311.

Suh, N.P. (2001), Axiomatic Design: Advances and Applications, Oxford University Press, New York.

Svetinovic, D. (2013), "Strategic requirements engineering for complex sustainable systems", Systems Engineering, Vol. 16 No. 2, pp. 165-174.

Tariq, M. et al. (2016), "Aircraft batteries: current trend towards more electric aircraft", IET Electrical Systems in Transportation, Vol. 7 No. 3, pp. 93-103.

Traub, L.W. (2011), "Range and Endurance Estimates for Battery-Powered Aircraft", Journal of Aircraft, Vol. 48 No. 2. https://doi.org/10.2514/1.C031027

Utterback, J.D. (1996), Mastering the Dynamics of Innovation, Harward Business School Press.

Zolfagharian, M. et al. (2019), "Studying transitions: Past, present, and future", Research Policy, No. April. https://doi.org/10.1016/j.respol.2019.04.012 